Trivent Publishing

(C) The Authors, 2018

Available online at http:/ / trivent-publishing.eu/

TRIVENT

Series: Applied Ethics: From Bioethics to Environmental Ethics

\title{
Is Death the Enemy? The Normative Power of Metaphor in Bioethics
}

\author{
Assya Pascalev \\ Howard University, USA, apascalev@howard.edu
}

Abstract: This chapter explores the role of metaphors in biomedical ethics. It maintains that metaphors have an important normative function in medical and moral deliberation: they affect thought and guide actions. We use as a case study the dominant metaphors of death and dying employed by critical care physicians. We identify three prevalent metaphors in end-of-life care: the WAR, TORTURE, and ART metaphors, and demonstrate their normative functions. The metaphors shape physicians' attitudes towards the dying, guide their reasoning and conduct, and influence their decisions on end-of-life care. We trace the moral implications of each metaphor for the treatment of the critically and terminally ill patients and show how the metaphors shape and constrain the moral deliberation of physicians. Our conclusions have far-reaching implications for bioethical reasoning and education, and could be applied in resolving ethical conflicts between patients and providers by identifying the conflicting metaphors, analysing their normative implications and actively constructing new shared metaphors.

Keywords: metaphor; moral reasoning; biomedical ethics; end of life care; the war metaphor; physician-patient relation.

This is an Open Access article distributed in accordance with the Creative Commons Attribution Non Commercial (CC-BY-NC-ND 4.0) license, which permits others to copy or share the article, provided original work is properly cited and that this is not done for commercial purposes. Users may not remix, transform, or build upon the material and may not distribute the modified material

(bttp:/ / creativecommons.org/licenses/by-nc/4.0/) 


\title{
Is Death the Enemy? The Normative Power of Metaphor in Bioethics
}

\author{
Assya Pascalev \\ "The greatest thing by far is to be the master of metaphor." \\ Aristotle, Poetics, 322 BC
}

\section{Introduction}

Metaphor consists in "seeing," understanding or speaking of one thing in terms of another, ${ }^{1}$ i.e., "Man is a wolf," "Time is money," "All the world's a stage." Traditionally, metaphor has been construed in purely linguistic terms as a powerful rhetoric device intended to convey images and emotions, and to persuade the listener. ${ }^{2}$ Outside literary discourse, however, metaphor has been viewed as unnecessary, dispensable and even dangerous because of its ability to "insinuate wrong ideas, move the passions, and thereby mislead the judgment; and therefore, wholly to be avoided" [2, p. 34]. This understanding of metaphor as ornamental and expendable coupled with the belief that metaphor has no place in serious fields such as science and philosophy has resulted in a lasting neglect of the role of metaphor outside literary discourse. As a result, philosophers have paid little attention to metaphor turning a blind eye to the presence of numerous metaphors in philosophical theories. Similarly, ethicists have largely failed to examine the role which metaphor plays in moral reasoning and, with a few exceptions, the metaphors, which operate in medicine and bioethics have received little philosophical scrutiny. ${ }^{3}$ Recent studies in linguistics and cognitive science challenge this received attitude by

1 In this most general definition, the word "thing" refers to any object, including physical objects, events and states of affairs.

${ }^{2}$ In Rhetoric, Aristotle states that metaphors "set the scene before your eyes" [1] (1410), enable one to "get hold of new ideas" [1] (1410b) and give "style clearness, charm and distinction as nothing else can" [1] (1405a).

${ }^{3}$ For a detailed analysis of the metaphors underlying Western philosophical thought, see [3] (Part III). 
showing that metaphors permeate language and play an important role in thought and action: metaphors operate in everyday language, science, philosophy and religion, and they function as conceptual frameworks, which shape the way we understand reality and our place in it $[3,4,5]$. This new conception of metaphor as a powerful instrument for understanding and even structuring reality, our perceptions and attitudes calls for an examination of the nature and functions of metaphor in fields traditionally considered metaphorfree, including mathematics, the natural sciences, medicine, philosophy and bioethics.

The purpose of this chapter is to explore the role of metaphor in biomedical ethics and its effects of the moral and professional conduct of physicians. It advances the view that metaphor has an important normative (action-guiding) function in moral reasoning and action, and that metaphors serve as vehicles of moral knowledge by allowing us to understand the values, concepts and principles associated with a particular metaphor. The focus of this chapter are the metaphors of death and dying employed by physicians in end-of-life care. I argue that physicians conceptualize the phenomena of death and dying through the use of metaphors, which have a normative function and prescriptive power. I identify three dominant metaphors of death and dying employed by physicians: the WAR, the TORTURE and the ART metaphors. ${ }^{4}$ I explicate the normative assumptions behind each metaphor and show that the metaphors influence physicians' attitudes towards the dying, shape physicians' moral and professional reasoning, structure their experience and influence medical decisions concerning the kind and quality of care at the end of life. Firstly, I analyse the WAR metaphor, which represents death as the chief enemy of medicine. The metaphor highlights the absolute value of life, encourages aggressive treatment and the use of medical technology regardless of the likely outcome. The metaphor ignores the patient's physical discomfort, and the psychological and emotional cost of the interventions. Next, I discuss the TORTURE metaphor representing dying as a technologically-aided torture. The metaphor emphasizes the patient's perceived quality of life and downplays the role of therapeutic intervention. The metaphor establishes the moral and psychological basis for limiting treatment. Lastly, I discuss the metaphor of DYING AS AN ART. It characterizes dying as the finale of a composition, and end-of-life care as orchestration. I conclude that in clinical settings, moral conflicts at the end of life are understood and resolved by the use and shift of metaphors of death and dying. The metaphors reassign moral responsibility, shape treatment decisions and change physicians' attitudes to the dying.

4 The three dominant metaphors of death and dying are identified and analysed at length in my dissertation Medical Metaphors of Death and Dying: An Ethical Analysis [6]. 


\section{What is a metaphor and why is it ethically significant?}

The word "metaphor" comes from the Greek term metaphora, which means "transfer" [7, p. 896], [8, p. 1]. Metaphors have a distinct basic structure with two components: one is the thing we are trying to understand or characterize, the other--the thing in terms of which we understand or characterize the first object. ${ }^{5}$ In philosophy, there exist two major positions on the nature and role of metaphor. The received view, which dominates most of the history of philosophy until the $20^{\text {th }}$ century, holds that metaphor is merely a figure of speech with purely decorative function. It lacks cognitive value and ought to be avoided in rational discourse. In the $20^{\text {th }}$ century, under the influence of cognitive science and linguistics, an alternative view emerges. This view called constructivism construes metaphor as essential to language and thought, and argues that it has important cognitive functions. The proponents of constructivism argue that metaphors are devices, which structure our experience, and help us to understand the world and our place in it. The constructivist view of metaphor could be traced back to the philosophical stance of I. Kant and F. Nietzhsce. However, it was articulated most clearly in the works of $20^{\text {th }}$ century rhetorician I. A. Richards and philosopher Max Black and further developed by linguist John Lakoff and philosopher Mark Johnson. Lackoff and Johnson's seminal books Metaphors We Live By [4] and Philosophy in the Flesh [3] analyze a huge number of metaphors, including the metaphors used in philosophical discourse. Drawing on research in cognitive science, Lackoff and Johnson (hereafter L\&J) show that metaphors function as conceptual frameworks, which can influence human actions, change cultural values, and shape social institutions.

It is beyond the scope of this chapter to undertake a detailed analysis of L\&J's view. For our purposes, it suffices to outline their central arguments for the normative significance of metaphor. L\&J begin by observing that metaphors are ubiquitous in all spheres of activity, including science and

5 The prevalent two-component view of metaphor has been criticized by some as too restrictive and inadequate. Opponents such as J. Soskice argue that the two-component structure is present only in metaphoric statements of the form " $\mathrm{X}$ is $\mathrm{Y}$ " but not in metaphors with different syntactic forms. Soskice cites counterexamples such as "The pages were covered with a writing script," "The children flew to the window," "He went about in a nimbus of despair" and phrases like "darker purposes," "rosy-fingered dawn," "bitter disappointments," and "sweet voices." She maintains that these are metaphoric expressions which lack two distinct components and that "to eliminate instances like these because they lack two explicit subjects would be to eliminate most of what we take to be metaphor" $[8$, p. 20]. Soskice notes that even those who subscribe to the two-components view, like S. Ullmann and M. Black, include expressions like "bitter disappointments" and "sweet voices" in their lists of metaphors $[8$, p. 20]. 
philosophy. We speak of time in terms of money ("You are wasting my time," [4, pp. 7-8]; we view love as a journey ("The marriage is on the rocks," "We are stuck' [4, pp. 64-68] and we discuss theories and arguments as if they are buildings, e.g., "We need to construct a strong argument," and if we fail, then "the argument collapses" [4, (p. 46]. Philosophical discourse also abounds with metaphors: recall Plato's metaphors of the Good as the sun, knowledge as light, and ignorance as darkness in the famous Allegory of the Cave. Descartes also uses a metaphorical conception of knowledge as seeing and Kant speaks of the moral community as the Kingdom of Ends. ${ }^{6}$ L\&J note that our most basic categories such as action, causation, time, and self are metaphoric in nature as is our ordinary conceptual system. The latter structures "what we perceive, how we get around in the world and how we relate to other people" [4, p. 3]. As part of our conceptual scheme, metaphors "structure how we perceive, how we think and what we do" [4, p. 4].

If $L \& J$ are correct and our conceptual system is indeed largely metaphoric in nature, then it follows that metaphor has also normative significance: "In all aspects of life... we define our reality in terms of metaphors and then proceed to act on the basis of the metaphors" [4, p. 158]. Since our intentional actions are guided partly by the features of the world, and partly by our goals, commitments and plans, then the metaphors, which underlie our understanding of the world and our perceptions, inferences, and plans also shape our actions and goals, and influence our patterns of deliberation. L\&J identify the specific cognitive mechanism, which brings about the normative power of metaphor. It results from the interaction between the two central components of metaphor. L\&J note that metaphor necessarily has two components: (1) a target domain, which we try to understand, and (2) a source domain, from which we borrow images and experiences in terms of which to understand the target domain. Thus, the "time is money" metaphor emerges when the target domain (time) is connected in a systematic way to the source domain (money, limited resource, valuable commodity). When we use a metaphor, we map one concept onto another forming a complex network of relations. The source domain consists of concepts, phenomena and experiences that are familiar and form a somewhat coherent whole. We use our knowledge about the source domain to understand the phenomena in the less familiar target domain. Relying on our knowledge of the source domain, we draw inferences about the target domain [4]. Consequently, we come to think of the target domain in terms of the objects, properties and relations of the source domain. The metaphoric expressions connect the characteristics of the target and source domains in non-arbitrarily way. These non-arbitrary

${ }^{6}$ For a detailed analysis of the metaphors underlying Western philosophical thought, see [3] (Part III). 
connections L\&J call "entailments." Thus "money" entails "a limited resource" which in turn entails "a valuable commodity". When we transfer the logic of the source domain onto the target domain, we end up with linguistic expressions such as "wasting time," "saving time" and "budgeting time." These expressions are structured by and make sense only in light of the chosen source domain. The latter act as a constraint on how we think about time, what we do with it ("borrow", "save", waste") and how we come to experience it. L\&J call this process "metaphoric mapping and structuring." The source domain serves as a frame of reference for understanding the target domain, and the pattern of ordering of metaphoric connections follows the structure and logic of the source domain. In such a way, a metaphor picks out features within the target domain which features would be deemed relevant on the basis of the elements or relations relevant in the source domain. The logic of the source domain highlights some aspects of the target domain, and hides others. When we think of time as money, we do not think of time as something else, i.e. TIME-IS-ART. The network of metaphoric entailments either fits our experiences, or fails to do so. If there is a fit, then the metaphor is deemed "apt," and the experience is organized according to the metaphoric entailments.

Whether or not a metaphor fits our experience is a complex question because one's experience is shaped by a multitude of factors including one's neurological and bodily constitution, culture and social institutions. Our culture and institutions in turn provide the context, in which some metaphors and ways of thinking would fit while other ways of thinking about those domains would be ruled out. The relation between metaphor, social reality and how we think about and understand this reality points to the elements of control and power inherent in the more complex metaphors, making metaphor a normative matter and, thus, a matter for ethical and political analysis. A metaphor can be used to exert power, to manipulate thought, and to misguide action because "the people who get to impose their metaphors on the culture get to define what we consider to be true-absolutely and objectively true" [4, p. 160].

The constructivist understanding of metaphor is particularly relevant to ethical inquiry, moral reasoning, and bioethics. It suggests that metaphors have normative import because of their capacity to shape moral concepts and to constraint cognition and moral reasoning. By the same token, metaphors become vehicles of moral knowledge and moral change because they allow us to deconstruct the values, concepts and principles associated with the use of a particular metaphor. Last but not least, the conceptual view of metaphor shows that although metaphor is constitutive of thought and understanding, any particular metaphor is in principle open to criticism and change because it 
is a human construct, which is contingent and need not make sense outside our Western conventions and institutional practices.

The analysis so far shows that understanding the role the metaphor plays in morality and evaluating the specific metaphors we employ becomes a legitimate task of ethical inquiry. Yet, there are very few attempts to identify and discuss medical metaphors from a bioethics perspective. ${ }^{7}$ In what follows, I draw on the constructivist theory of metaphor to identify the dominant medical metaphors of death and dying and use them as a vehicle to understand the values, interests and commitments of medical practitioners.

I approach the medical metaphors of death and dying from the perspective of the medical workers in intensive care because, in contemporary American society, about $50 \%$ of Americans die in hospitals under intensive care [12]. This makes the ICU the place where both patients and physicians tend to encounter death. My analysis utilizes a variety of sources including an in-depth qualitative study of ICU by medical sociologist Robert Zussman [13] and my own observations at two leading medical institutions. My analysis of the philosophical and cultural roots of the metaphors relies on the works of French historian Philip Aries [13, 14], anthropologist I. Illich [16] and philosopher R. Momeyer [17]. I also draw on the studies of medical sociologists Claudine Herzlich and Janine Pierret [18].

The empirical material reveals three different sets of images of death and attitudes to dying employed by the medical professionals in the ICU. They are organized around three distinct metaphors: the WAR metaphor, the TORTURE metaphor and the ART metaphor. I isolate the target and source domain of each metaphor, I analyse its entailments and their normative consequences, and assess the metaphors from a patient-cantered perspective.

\footnotetext{
${ }^{7}$ In an article titled Metaphors and Models of Doctor-Patient Relationships: Their Implications for Autonomy, bioethicists James Childress and Mark Siegler identify five dominant metaphors (or models) used to characterize the physician-patient interaction in bioethical literature. The authors indicate that the metaphors play a descriptive as well as prescriptive role and need to be assessed critically [9]. In his book The Foundations of Bioethics, Tristram Engelhardt discusses the metaphor of the captain of the ship as a description of the traditional role of the physician [10]. More recently, Swedish scholar Anders Nordgren has argued for the significance of metaphors in bioethics [11]. Except for these sporadic efforts, bioethicists and philosophers have not explored systematically the ways in which metaphors influence medical practice and their effects of on medical decision-making and the moral deliberation of physicians are still to be explored.
} 


\section{The WAR Metaphor of Dying 8}

\section{The Structure and Meaning of the WAR Metaphor}

The WAR metaphor represents the chronologically first medical response to the threat of death in the ICU. It conceptualizes critical care as warfare and death as the enemy of the physician. The gist of the metaphor is captured in the statement of an ICU physician: "we believe in the cure, and we look at death as the enemy and we are gladiators in the battle against disease..." [13, p. 107]. The source domain is war, the target domain is death in the ICU. The statement reveals a particular perception of death as the biggest foe of medicine. Treatment decisions and medical interventions are described in militaristic terms, e.g., physicians administer "batteries of tests," and prescribe "armies of antibiotics." The WAR metaphor exemplifies physicians' active, even aggressive attitude to the challenges of life-threatening illness and death, which gives rise to a militaristic rhetoric. This mode of conceptualizing death and dying has far-reaching consequences for the patients. Zussman writes: "First, virtually all patients are treated actively in the intensive care unit at least at the time of their admission" [13, (p. 107]. All resources are mobilized and aggressive methods of treatment are commonly applied. As a result of this professional response, the patient is likely to receive maximum attention from a qualified staff; she can benefit from the most advanced medical technologies and has better chances for survival. Even if the patient has a bad prognosis, her life can at least be prolonged. The WAR metaphor reveals a peculiar, yet characteristic mixture of associations among different notions and images. The meaning of cure, illness and death are intertwined and disease talk is conflated with death talk. Such a framing of death and dying is deeply rooted in Western culture. ${ }^{9}$ According to French historian Aries, it is a distinct feature of modern medicine that death becomes a part of "the disease of which it is one of two

8 I offer a detailed reconstruction of the WAR and TORTURE metaphors in [19, pp. 219-236].

9 More particularly, in the U.S.A., death and the medical profession have become permanently linked together in medical practice and the public's perception since the late $19^{\text {th }}$ and early $20^{\text {th }}$ centuries. Such a link becomes possible when the institution of hospital emerges as the proper locus of both medical treatment and death. It offers to physicians optimal conditions for applying complex and technologically advanced procedures which are impossible to accomplish outside the institution. Thus, the clinical environment significantly enhanced physicians' ability to combat illness, pain and suffering, and ultimately death. Therefore, in the hospital, the struggle with death becomes the natural continuation of the therapeutic efforts of physicians. As a result, treatment and dying were institutionally conjoined. From that moment on, death became part of the province of medicine and today medicalized death is practically the only mode of dying faced by individuals in the U.S.A. 
possible outcomes, the other being recovery" [15, p. 358]. The death of the patient comes to be equated with a medical failure. This image of death as the enemy is evoked not only by the medical staff, it is adopted also by the patients. They use the WAR metaphor, when trying to communicate their experiences in the unit. Thus, a patient who underwent intubation explains: “... all these doctors are taking care of you, you know. They are fighting for your life. They don't know you, but they're there fighting for your life" [13, p. 94]. The patient's account illustrates the pervasive image of death as the enemy and the power of medical discourse to penetrate the patterns of thinking of lay people. The institutional mission of the ICU determines the framework within which the image of death as an enemy is construed and reinforced: as in war, the ICU interventions take place after the outbreak of a crisis--a lifethreatening or acute illness. For the ICU staff, death comes to be perceived as the unwanted result of an organ-system failure, against which the staff consolidates its efforts. Thus, the image of death as an enemy emerges out of the very mission of intensive care. As in wartime, the ICU staff is "armed" with complex equipment which is impossible to access outside the unit. Here, the most advanced and sophisticated medical technologies are constantly applied. Vasopressors, ventilators, apparata for haemodialysis are only a small portion of the intimidating armaments employed in the combat with death. But, perhaps the most eloquent evidence for the militaristic profile of the ICU is its genesis. The emergence of ICUs is the result of earlier efforts of American military officers to secure medical care for "the more seriously ill but salvageable soldiers." ${ }^{10}$ Zussman characterizes the ICU is the subunit in a hospital, where the active orientation of American medicine reaches its high point. The following statement of an ICU resident illustrates this perception: "You send a patient to the [ICU] to escalate the battle, so this is the next logical step in that battle" [13, p. 107].

The image of death as an enemy can be seen as a manifestation of the profound anxiety that we, human beings, experience, when faced with the fact of our mortality. This negative perception is part of the more general value orientation typical of the $20^{\text {th }}$ century Western society manifested in what Illich calls "the total war to all death-dealing agencies" [16, p. 202]. While in the past, people in the Western world felt at one with nature and saw death as part of it, from the $17^{\text {th }}$ century on, a rapid rise of science and technology took place bringing with it the rise of rationalism and its "faith in progress and its triumph over nature" [15, p. 608]. Death, which was associated with nature, began to be viewed as savage, fearful and evil $[14$, p. 56]. It is in this modern, death-

10 This view on the genesis of Intensive Care Unit is suggested in Thompson [20, p. 225]. 
denying sentiment that the socio-cultural roots of the WAR metaphor can be found.

The new understanding of death as natural led to the accumulation of medical knowledge and professional skills by physicians. ${ }^{11}$ Consequently, the abilities of doctors to control the outcomes of specific diseases, and to provide cure and prolong the lives of their patients, increased. Physicians became an embodiment of the power of science and were admired because of their perceived ability to push away the patient's suffering and death. This view gave rise to the myth that physicians also "had power over death" [16, p. 195]. As a result, death becomes medicalized and it remains medicalized today. From the standpoint of the physician of today, death is perceived as "a kind of medical disaster" [13, p. 37] - an understanding that gives rise to an extreme negative attitude towards death in medical settings.

\section{The Normative Functions of the WAR Metaphor}

This metaphor expresses a negative attitude to death and sanctions the active, even aggressive stance towards dying in the ICU. The active appeal of the WAR metaphor corresponds to the humane mission of the medical profession, which is fundamentally oriented against suffering and pain. Respectively, the challenge for the physician is to balance two distinct professional attributes--compassion and compulsiveness. They correspond to the physician's stable obligations to search for diagnosis, to intervene in the name of treatment, and to alleviate suffering. The ICU environment enhances physicians' actual and perceived ability to combat illness, pain and suffering and creates the hope that it can ultimately also combat death. Consequently, the WAR metaphor is evoked mainly when physicians believe that the patient's life can be saved. The metaphor shapes an expectation that the outcome of the physician's efforts will be positive. By implication, the WAR metaphor connotes that the patient's death is a medical failure. This particular representation of death expresses the self-confidence of health professionals in their ability to accomplish the humanitarian mission of medicine to cure, to protect the patient's life, and to save it, when endangered. Therefore, the WAR metaphor can be interpreted as a manifestation of the self-awareness of the medical profession of its own power. The metaphor embodies the professional ethos of Western medicine bequeathed through the Hippocratic Oath and reinforced by the Judeo-Christian tradition.

11 At that time, physicians had at their disposal not only the achievements of various scientific disciplines, but were also able to accumulate specific medical knowledge by performing dissections of human bodies that had been sacred once, but were so no longer. 


\section{Critical Evaluation}

The attitude of death denial that gives rise to the WAR metaphor has been challenged by many a contemporary scholars. Illich and Momeyer argue that the militaristic rhetoric and the faith in technology create a clinical illusion "that our struggle will result in some sort of abiding victory" over death. This unexamined belief rests on perceived or desired, but not actual professional abilities of physicians. ${ }^{12}$ Such views are conducive to excessive medical aggressiveness and encourage "an obsessive kind of medicine conceived as a constant struggle against death" [17, p. 158]. The underlying concerns are that the medical techniques for conquering death are distressing for the patients, too expensive for society, and there exists no strong evidence that they reduce mortality or promote patient's quality of life. ${ }^{13}$ A major criticism of the WAR metaphor is that it prompts contemporary medicine to go beyond what patients and society may see as acceptable and reasonable treatment.

\section{The TORTURE Metaphor of Dying}

\section{The Structure and Meaning of the TORTURE Metaphor}

The TORTURE metaphor expresses the physicians' experiences in treating patients whose condition is seen as hopeless. The meaning of the metaphor is captured in a joke popular in two ICUs studied by Zussman:

Missionaries are in a tribal land and are captured by the natives. They are brought before the chief and the chief asks one of the missionaries, 'What would you prefer, cheechee or death?' and the first missionary says cheechee, at which point the entire tribe descends on him, ties him to a pole. Each member of the tribe [beats] him. And then the rope [is] tied around his hands, and he is dragged about a mile losing bits and pieces of himself. And [he's] thrown over into a ravine. The other missionary looks horrified at what is going on. And the chief comes back to him and asks him, 'Well, what do you prefer, death or cheechee?' The missionary...says... 'I would prefer death.' The chieftain says, 'Yes, but first a little cheechee' [13, p. 111]

12 Among those contemporary scholars who raise serious doubts regarding the legitimacy of the faith and expectations invested in medical profession is Illich [16]. A more recent critique of the cultural authority of medicine is offered by Herzlich and Pierret [18, Ch. 11].

13 These criticisms, directed in particular to Intensive Care Unit, are offered in Relman [21, pp. 1252-1253]. 
"Cheechee" is used interchangeably with the word torture to signify death which is certain, but which must be preceded by extensive treatment. The following explanation of an ICU resident articulates the meaning of the metaphor: "[T]orture is a word used to say that we are putting someone through pain without reason, without reasonable hope that we can reverse the pain he has" [13, pp. 111-112]. Like the WAR metaphor, the TORTURE metaphor is constructed relative to the expected therapeutic results. However, contrary to the WAR metaphor, the image of torture emerges when the foreseen outcome is negative. Zussman observes that, typically, "cheechee" is evoked either (i) when death is certain, or (ii) in cases of incurable patients, or (iii) when "some treatments may simply extend a life that is already wrecked by suffering" [13, p. 110]. Hence, the TORTURE metaphor reflects professional impotence of physicians. It highlights considerations about the patent's perceived quality of life and downplays the role of therapeutic intervention. The bioethics principles behind this metaphor is the principle of nonmaleficence (primum non nocere: above all, do no harm). The metaphor establishes the basis for limiting treatment and abstaining from the use of medical interventions to prolonging life. The experience of impotence and the image of dying as torture have a profound effect on the self-image of health professionals. In light of the TORTURE metaphor, the technical means of medical profession, which lend to it its sense of efficiency and ground its selfconfidence, undergo an intriguing transformation in the imagination of medical workers. The same technological means which physicians saw as instruments of empowerment in the WAR metaphor (tubes, IVs, ventilators) come to be perceived as inquisition devices under the TORTURE metaphor. On the face of it, the metaphor expresses a concern for the patient's suffering. Yet, it is invoked at the end of life when most ICU patients are unconscious, comatose, or in vegetative state. Such patients do not experience suffering. The suffering captured by the metaphor is the suffering, anguish and frustration of the medical staff facing the limit of medicine. This metaphor is at least as much self-reflective as it is about the patient's well-being.

\section{The Normative Functions of the TORTURE Metaphor}

The TORTURE metaphor expresses the moral awareness of physicians that a given treatment is futile, and that it inflicts pain. Because of that, the TORTURE metaphor seems to reflect medical considerations that are ultimately patient-cantered. However, the analysis reveals that this is not the case. Zussman notes that since pain is very difficult to measure, neither the doctors, nor the nurses he interviewed "are at all sure how much pain their patients are suffering” [13, p. 112]. Hence, the perception of dying as a torture is not born out of pure compassion. Rather, in the context of intensive care, 
torture becomes, "a self-reflective concept...Torture refers not just to the suffering of patients, but also to the suffering of doctors and nurses" [13, p. 113].

The TORTURE metaphor reflects the self-reproach of medical workers when they face the limits of medicine marked by the presence of imminent death. At first glance, this frustration seems to stem from a false dilemma that physicians set for themselves. For to cure a patient at the expense of great suffering, or not to cure her does not seem a genuine dilemma, provided the patient is going to die anyway. But what may seem as an exaggerated frustration is, in fact, an expression of a two-fold crisis of the occupational identity of physicians. As Zussman notes "[m]edicine is caught between two sometimes conflicting values: on the one hand, an ethic of intervention and treatment; on the other hand, an injunction to do no harm" [13, (p. 110]. Thus, the image of torture is evoked, when the harmonious coexistence of compulsiveness and compassion is disturbed. It brings in focus two types of problems, which confront the medical profession today. First, the metaphor expresses a tension within the medical profession between the two fundamental imperatives of medicine: to cure (compulsiveness) and to relieve suffering (compassion). The minimal expectation that medical professionals should meet is that "[i]f they cannot always cure, they can at least minimize pain" [13, p. 110]. From this perspective, the TORTURE metaphor expresses the self-reproach of physicians that by subjecting their patients to futile treatments, they go "beyond the point where you should artificially prolong their life... On the other hand, a willingness to withhold treatment in the name of compassion requires a renunciation of the compulsive search for treatment," observes Zussman [13, p. 110]. Consequently, the metaphor has explicit normative connotations. It prohibits medical workers from inflicting what is perceived as uncompensated, and therefore, unjustified suffering. It can be concluded that the TORTURE metaphor communicates a particular moral stance intrinsic to the nature of medicine as a profession.

The other facet of the occupational crisis of which the TORTURE metaphor of dying becomes a symptom, is determined by conditions external to the medical profession. They have to do with the existing social constraints on the professional autonomy and the cultural authority of physicians. By engaging themselves in procedures that artificially prolong the physiological existence of terminally ill patients "beyond any reasonable prognosis," medical workers develop concerns that they are involved in useless activities and their efforts are not properly directed. Yet, they cannot stop a futile treatment only on the basis of their own judgment, because institutional health care is part of the complex network of society. There, the actions of physicians have to comply with the public demand "to get everything done" and with the scrutiny of legislators, patients' families and hospital administrators. Ultimately, the 
metaphor of dying as TORTURE manifests physicians' awareness that they are not the sole masters in their province. The TORTURE metaphor goes well beyond consideration about patients' interests; it signals the awareness of doctors that they cannot autonomously 'set their own agenda." The TORTURE metaphor indicates a reversal in both the professional and societal perception of death. With the help of medical technology, dying becomes a continual process of discrete medical victories and losses through which the patient as a person vanishes. The TORTURE metaphor can be interpreted as physicians' own reproach to these social and cultural tendencies that strip human death from its personal, spiritual and moral significance.

\section{Critical Evaluation}

The TORTURE metaphor embodies an image of death which is incompatible with the WAR metaphor. It tempers physician's activism, brings forth considerations about the patient's perceived quality of life, and engenders willingness on the part of physicians to limit treatment and to abstain from the use of extraordinary means for prolonging the patient's life. The metaphor emphasizes the moral and technical limits to the power of medicine and urges a reconsideration of its professional tasks. The metaphor displaces physicians' commitment to compulsive care with considerations of futility and compassion; aggressive treatment yields to palliative care and physicians' discretion yields to the public demands for patient's autonomy. The image of dying as torture expresses physicians' awareness of the growing societal mistrust of the medical profession and represents the response of contemporary health-care providers to the public control over the practice of medicine in the USA. Last but not least, the TORTURE metaphor urges physicians to look for alternatives to aggressive care at the end of life. It allows them to acknowledge the need for limiting treatment and offers a conceptual framework for justifying the withholding or withdrawal of medical treatment as a legitimate aspect of end-of-life care.

\section{The ART Metaphor of Dying}

\section{The Structure and Meaning of the ART Metaphor}

The ART metaphor is an attempt to resolve the tensions by re-conceptualizing dying, death, and the proper role of medicine. The metaphor characterizes the process of dying as the finale of a composition and end-of-life care as the orchestration of the finale. It involves multiple performers (the physician, the health care team and the patient's family) and comprises various conflicting elements such as the responsibility to maintain life, the relief of suffering (beneficence), the imperative to respecting the patient's wishes (autonomy) and 
not to harm (non-maleficence). The physician is viewed as the conductor of the musical piece. She strives to coordinate the tasks of those involved and to harmonize the conflicting elements so as to achieve harmony (the unity of the piece) and to attain the desired end (the finale, an "optimal," "good" or "dignified" death).

The ART metaphor of dying and death is the most recent way of conceptualizing the process of dying and the nature of end-of-life care in the medical and bioethics literature. The earliest instances of the metaphor can be found in the personal narratives of physicians regarding their experiences in end of life care in the 1990's [22, pp. 9, 25, 29, 59]. However, the most explicit articulation of the ART metaphor can be found in Stuart Youngner's article "Orchestrating a Dignified Death in the Intensive Care Unit" [23]. He evokes the ART metaphor in the context of a discussion of the moral and professional responsibilities of critical care physicians in the contemporary clinical environment of the ICU. This environment combines the availability of advanced medical technology allowing physicians to control death and "to postpone it... in almost every instance" [23, p. 1617] with the awareness of growing health care costs, scarce medical resources and a strong emphasis on the patient's autonomy. According to Youngner, "in these circumstances, the critical care physician cannot avoid the responsibility of orchestrating death by balancing factors such as the patient's autonomy and best interests, medical uncertainty and futility, and notions of 'passive' (permissible) and 'active' (forbidden) euthanasia" [23, p. 1617]. The central role in the process of orchestrating death is relegated to the physician, who is the creator of the artwork: "The critical care physician can be likened to a conductor/composer, struggling to balance and blend various clinical, legal, moral, psychological, spiritual, and, increasingly, economic influences to permit patients an optimal death in less than optimal circumstances" [23, p. 1617]. This emphasis on the physician as the composer of the artwork, as opposed to the patient whose life and death are at stake, begs the question whether the metaphor is apt and whether the central role of the physician is morally justified. To answer the question, we need to place the metaphor in context.

In Youngner's article, the ART metaphor is evoked in the same clinical setting, the ICU, as the WAR and TORTURE metaphors, and it is applied to the same phenomena to which the other two metaphors are applied. All the patients discussed by Youngner are critically or terminally ill; they are clinically unstable, frightened and depressed. Frequently, the patients whose deaths are being orchestrated are comatose, delirious and unable to communicate due to intubation. Yet, the ART metaphor gives a new meaning to these settings and phenomena, and construes the corresponding actions and events in a different way. The source domain of the new metaphor is art, and more particularly, the performance arts and music. The target domain is the process of dying and 
death. The ART metaphor highlights certain aspects of dying and medical care at the end of life, and hides others. As a result, the metaphor makes physicians' experiences coherent in the face of demands and obligations that appear contradictory and conflicting when we try to understand them through the lenses of the other two metaphors. By employing the concepts of art and orchestration, the metaphor highlights the creative character of caring for the dying and its spiritual dimensions. It acknowledges the individuality of the dying and the social context of the patient's death. This is expressed in the collaborative nature of orchestration and in the reference to the family and the health care team. All this seems to suggest that, at least on the face of it, the ART metaphor is patient-centered. Yet, in the conditions of intensive care, the patient's ability to exercise autonomy and decision-making power is restricted or altogether absent: "In short, the balance of power and control, if not moral authority, inevitably rests with the critical care physician and staff," concludes Youngner [23, p. 1617]. The language of "orchestration" implies that, in the treatment of critically and terminally ill patients, the physician, and, in a lesser degree, the health care team has significant freedom of interpretation. The physician has to exercise discretion in selecting the appropriate treatment for each patient, deciding how much information to present to the patient and the family, and how much involvement to encourage. The physician discretion entailed by the ART metaphor is supported by the considerable degree of uncertainty in medical decision-making and the highly individual character of clinical judgments. The discretion of physicians, medical uncertainty and the individuality of clinical cases give rise to the idea of improvisation in medicine and support the analogy between art and end of life care.

The ART metaphor gives a new meaning of the process of dying itself and transforms the way we think of death. In virtue of this, the metaphor not only organizes the experiences, thought and actions of physicians. It also provides a structure for thinking about and understanding the needs and experiences of the dying patients. The new understanding of dying and death expressed in the ART metaphor is based on the existing, culturally shared conceptions of art, musical composition and orchestration. In contemporary Western culture, orchestration is a special kind of activity: it is creative, cooperative, and, to a certain extent, unpredictable. When extended to death, dying and end-of-life care, the term "orchestration" implies that the physician has (some) control over death in virtue of the availability of and control over various means for timing death in the ICU. Youngner writes, "Even when death is imminent, we have interventions that can postpone it for hours, days, or weeks in almost every instance. This is especially true in the modern, technology-dense, intensive-care unit (ICU), where medicine and highly trained health professionals can monitor, support, or substitute for nearly every life function" [23, p. 1617]. 


\section{The Normative Significance of the ART Metaphor}

The ART metaphor incorporates death and dying into the sphere of medical care and re-directs the physician's attention and efforts to the process of dying. The metaphor is a search for a balance between the fight for life and the acceptance of death. Death is no longer viewed merely as the limit or failure of medicine. Accepting the patient's death no longer amounts to abandonment. By extending the meaning of art and orchestration to the process of dying and death, the ART metaphor re-conceptualizes these experiences and the intrinsic conflicts associated with them. The metaphor allows health care workers to see dying, death and the moment of letting go as part of a meaningful, creative and unique experience. In such a way, the metaphor transforms the traditional goals of medical care and the meaning of the daily activities of the health care team. Within the framework of the ART metaphor, the goal of medicine is to facilitate the patient's transition in the process of dying and to facilitate a good death. It suggests that care for the dying should no longer be considered futile, nor should the patient's death be viewed as a professional failure. The efforts of the physicians are justified and various forms of medical treatment are deemed appropriate as long as they lead to the desired end, the least worst death. In such a way, the metaphor sanctions non-treatment as a legitimate option and withdrawal of medical treatment as a morally appropriate medical means to achieving a good death. The quintessence of the ART metaphor is captured nicely in a remark by J. Billing, an internal medicine associate, who notes that "personal notions of comfort, of "death with dignity," of an appropriate way to die, guide the work. Prolongation of life may be a goal, but so may be the avoidance of measures which promote survival" [24, p. 35]. The ART metaphor thus endorses good ("optimal," or "appropriate") death as a proper goal of medicine. It urges physicians to regard the individual steps in the treatment of a dying patient as parts of a larger, meaningful process, and to see themselves as active participants in this process.

The collaborative nature of the ART metaphor expands the social context of medical care at the end of life to include the loved ones of the patient. This aspect of orchestration is highlighted by Robert Truog: "Thoughtful and compassionate clinicians often will orchestrate the death of a patient specifically to ensure that the patient's loved ones are left with 'the least worst' memories possible" [25, p. 25]. Another major normative effect of the ART metaphor is that it facilitates a change in physicians' attitudes to death and a movement away from the belief in the absolute value of life.

The major weakness of Youngner's ART metaphor is its portrayal of the role of the patient in the process of orchestration. On the surface of it, the metaphor appears patient-centered: it highlights the goal of allowing a good death, and underscores the individuality of end-of-life care. On a closer 
examination, however, it is clear that the patient remains passive and isolated from the decisions concerning his own life and death. "Ideally, the ultimate authority rests with the patient. However, the realities of critical care make realizing this ideal extremely difficult," argues Youngner [23, p. 1617]. While in theory, the metaphor recognizes the value of the patient's autonomy, it breaks down when faced with the constraints of care in the ICU. This suggests that the structure of intensive care does not allow for truly patient-centered care at the end of life and that the ART metaphor, as employed by Youngner, remains physician-centered.

It should be noted that the ART metaphor itself does not necessarily entail the physician-centered interpretation advanced by Youngner. Many physicians have been critical of the power and dominance of the physician in end-of-life care. As Steven Miles notes, "Death belongs to families and to patients, not to the medical profession. It is failure twice when the medical profession steals the death and fails to palliate. We should be helpful stagehands, not inept stage managers" [26, p. 29].

There are two other ways in which the ART metaphor "misses" reality and masks important facts about care for the dying. First, the language of orchestration implies a sustained, coordinated, collective effort to achieve the desired, pre-established goal. But studies show that clinical decision making at the end of life does not follow a controlled, reflective model but takes a "cascade" form [27]. The final decision is the result of a long and intense bargaining and negotiation between the physician, the family and, less frequently, the patient herself. The negotiation "occurs in the context of differential power relations among professionals and patients and families" [27, 252]. The process begins with the illusion of choice, which the physician presents to the family and ends with the sharing of moral responsibility for the patient's death with either the family or the patient himself.

Lastly, the concept of orchestration could be misleading because it implies harmony and coordination within the health care team, which rarely exist. The reality in large hospitals is different: the physicians rotate frequently, they do not have long-term relationship with their patients, and the medical team often is unaware of the patient's wishes and values. The discourse of art and orchestration creates the impression of continuity of care, cooperation and good rapport between physicians, patients and the patient's family. The metaphor does not challenge the institutional context of end-of-life care and the limitations this context imposes on achieving optimal care. The metaphor addresses the needs of the physician, the medical team and the family much more aptly than it does the needs and interests of the dying patient. The analysis of the ART metaphor suggests that, while the emergence of new metaphors of death and dying can contribute to the improvement of end-oflife care, metaphors alone are not sufficient to bring about a real change in the 
treatment of the dying. For a genuine change to occur, the displacement of conceptual metaphors must also prompt changes in the institutional context within which the metaphors are imbedded.

\section{Conclusion}

The moral and professional experience of critical care physicians is shaped by the dominant metaphors of death and dying, which operate in that context, namely, the WAR, TORTURE and ART metaphors. They structure physicians' attitudes towards death and dying, influence their reasoning and behaviour, and influence their decisions concerning the kind and quality of care for the critically ill. The metaphors reflect certain societal interests, cultural and moral values and prevailing professional assumptions. This is not to suggest that metaphor should be avoided in medical discourse as subjective and dispensable. On the contrary, it is my view that it is unavoidable to use metaphors when talking and deliberating about medical and moral maters in clinical context, and especially when end-of-life care is concerned. The medical metaphors of death are context-dependent and affect how physicians understand their tasks and responsibilities, how they categorize the patient's condition and how they choose between alternative modes of treatment. Moral dilemmas at the end of life are understood and resolved by the use and shift of metaphors of death and dying which metaphors reassign moral responsibility, shape treatment decisions and change physicians' attitudes to the dying and to the mission of medicine. The connection between metaphors, institutional context, and the treatment of the patient is not accidental but points to the mutual dependence between normative constraints, underlying values, and institutional commitments. For this reason, we ought to recognize the metaphors we use and to evaluate their normative connotations. One important practical implication of our conclusion is that any effort to change the medical attitudes to death and to improve the care for the dying presupposes an understanding of the medical metaphors of death and dying. Such changes and improvements would involve the development of new metaphors through the process of education and socialization of physicians and would require changes in the institutional structures, legislation and policies, in which the medical metaphors of death are imbedded.

\section{References}

[1] Aristotle. The Rhetoric of Aristotle. Trans. L. Cooper. Englewood Cliffs, N.J.: Prentice-Hall, 1960.

[2] J. Locke. Essay Concerning Human Understanding. Ed. A.C. Fraser. New York: Dover, 1959. 
[3] G. Lakoff and M. Johnson. Philosophy in the Flesh: The Embodied Mind and Its Challenge to Western Thought. Basic Books, 1999.

[4] G. Lakoff and M. Johnson. Metaphors We Live By. Chicago: University of Chicago Press, 2003.

[5] R. Gibbs. The Cambridge Handbook of Metaphor and Thought. New York: Cambridge University Press, 2008.

[6] A. Pascalev, Medical Metaphors of Death and Dying: An Ethical Analysis. PhD dissertation, Dept. of Phil., Bowling Green State Univ., Ohio, 2002.

[7] Chamber English Dictionary. Cambridge: Chambers, 1988.

[8] J. Soskice, J. Metaphor and Religious Language. Oxford: Clarendon Press, 1985.

[9] J. Childress and M. Siegler. "Metaphors and Models of Doctor-Patient Relationships: Their Implications for Autonomy." Theoretical Medicine and Bioethics 5 (1984).

[10] T. Engelhardt. The Foundations of Bioethics. New York: Oxford University Press, 1984.

[11] A. Nordgren. "Ethics and Imagination." Theoretical Medicine and Bioethics 19 (1998).

[12] Centers for Disease Control, "Worktable 309: Deaths by place of death, age, race, and sex: United States,"

bttp:/ / www.cdc.gov/nchs/data/dvs/Mortfinal2005_worktable_309.pdf 2005. Accessed February 3, 2014.

[13] R. Zussamn. Intensive Care: Medical Ethics and the Medical Profession. Chicago: The University of Chicago Press, 1992.

[14] P. Aries. Western Attitudes Toward Death: From the Middle Ages to the Present. Baltimore: Johns Hopkins University Press, 1974.

[15] P. Aries. The Hour of Our Death. London: Penguin, 1981.

[16] I. Illich. Medical Nemesis: The Expropriation of Health. New York: Pantheon Books, 1976.

[17] R. Momeyer. Confronting Death. Indiana University Press, 1988.

[18] C. Herzlich and J. Pierret. Illness and Self in Society. Baltimore: Johns Hopkins University Press, 1987.

[19] A. Pascalev. "Medical Images of Death and Dying in the Intensive Care Unit." Journal of Medical Humanities 17 (1996).

[20] L. Thompson. "Structure of Critical Care: An Overview." In Major Issues In Critical Care Medicine. Ed. J. Parillo and S. Ayers. Baltimore: William and Wilkins, 1984.

[21] A. Relman. "Intensive Care Units: Who Needs Them?" New England Journal of Medicine 302 (1980).

[22] American Board of Internal Medicine, Caring for the Dying: Identification and Promotion of Physician Competency Personal Narratives, 1996.

[23] S. Youngner. "Orchestrating a Dignified Death in the Intensive Care Unit.” Clinical Chemistry 36 (1990). 
[24] J. Billings. "On Being a Reluctant Physician.” American Board of Internal Medicine. Caring for the Dying: Identification and Promotion of Physician Competency Personal Narratives (1996).

[25] R. Truog. "Is It Time to Abandon Brain Death?" Hastings Center Report 27 (1997).

[26] S. Miles. "Stage Managing Death." Caring for the Dying: Identificaton and Promotion of Physician Competency. Educational Resource Document 29 (1996). [27] J. Slomka. "The Negotiation of Death: Clinical Decision Making at the End of Life." Social Sciences and Medicine 35 (1992). 